\title{
Flora da Usina São José, Igarassu, Pernambuco: Polygalaceae
}

\author{
Flora of the Usina São José, Igarassu, Pernambuco: Polygalaceae
}

Débora Maria Cavalcanti Ferreira ${ }^{1,3}$, Jorge Irapuan de Souza Barbosa ${ }^{2}$ \& Marccus Alves $^{1}$

\begin{abstract}
Resumo
Polygalaceae é amplamente distribuída nas regiões tropicais e temperadas. Apresenta aproximadamente 1.300 espécies, com 197 ocorrentes no Brasil. Para os fragmentos de floresta atlântica estudados na área da Usina São José, em Igarassu, Pernambuco foram reconhecidos cinco gêneros e nove espécies. São elas: Asemeia martiana, A. violacea, Bredemeyera laurifolia, Diclidanthera laurifolia, Polygala galioides, $P$. longicaulis, $P$. paniculata, $P$. trichosperma e Securidaca diversifolia. As espécies da área são diferenciadas principalmente pelo hábito, ocorrência e formato de glândulas na base do pecíolo e do pedicelo, ápice da carena, tipo de fruto, formato das sementes e ocorrência de apêndices nas mesmas. $O$ tratamento taxonômico conta com chave de identificação, descrições, ilustrações e comentários para os táxons.
\end{abstract}

Palavras-chave: Brasil, florística, inventário, Mata Atlântica, taxonomia.

\begin{abstract}
Polygalaceae is widely distributed in tropical and temperate regions. It presents approximately 1,300 species, with 197 occurring in Brazil. Five genera and nine species were recognized to the fragment of Atlantic Forest in the area of Usina São José, Igarassu, Pernambuco. The taxon included in this taxonomic study are: Asemeia martiana, A. violacea, Bredemeyera laurifolia, Diclidanthera laurifolia, Polygala galioides, P. longicaulis, P. paniculata, P. trichosperma e Securidaca diversifolia. They are mainly recognized by the habit, the occurrence and shape of the glands on the base of the petiole and pedicel, carina apex, fruit type, shape of seeds and occurrence of appendages on them. Identification key, descriptions, illustrations, and comments for the taxa are also provided.
\end{abstract}

Key words: Brazil, floristics, inventory, Atlantic rainforest, taxonomy.

\section{Introdução}

Polygalaceae (Fabales, de acordo com o APG IV 2016) é amplamente distribuída nas regiões tropicais e temperadas e apresenta cerca de 1.300 espécies (Paiva 1998; Marques \& Peixoto 2007). No Brasil, está representada por 197 espécies organizadas atualmente em 11 gêneros (BFG 2015), quatro destes gêneros (Acanthocladus Klotzsch ex Hassk., Asemeia Raf. emend. Small, Caamembeca J.F.B. Pastore e Gymnospora (Chodat) J.F.B. Pastore) foram elevados a categoria genérica recentemente baseados em evidências filogenéticas, anteriormente eram considerados subgêneros (Acanthocladus, Hebeclada, Ligustrina e Gymnospora, respectivamente) de Polygala L.
(Pastore et al. 2010; Pastore 2012; Pastore \& Abbott 2012; Pastore \& Moraes 2013). Os 11 gêneros com o número de espécies que ocorrem no Brasil são: Acanthocladus (5 spp.), Asemeia (19 spp.), Barnhartia Gleason (1 spp.), Bredemeyera Willd. (11 spp.), Caamembeca (9 spp.), Diclidanthera Mart. (3 spp.), Gymnospora (2 spp.), Monnina Ruiz \& Pav. (14 spp.), Moutabea Aubl. (8 spp.), Polygala L. (100 spp.) e Securidaca L. (25 spp.) (BFG 2015).

Os representantes da família Polygalaceae são desde ervas até lianas, apresentam folhas simples, alternas, verticiladas ou verticiladas e alternas, as inflorescências são racemos, panículas ou fascículos umbeliformes, as flores são bissexuadas, as sépalas são pentâmeras, em uma ou duas séries,

\footnotetext{
${ }^{1}$ Universidade Federal de Pernambuco, Depto. Botânica, Av. Prof. Moraes Rego 1235, 50670-901, Recife, PE, Brasil.

${ }^{2}$ Instituto de Pesquisas Agropecuárias de Pernambuco - IPA, Av. Gen. San Martin s/n, 50670-900, Recife, PE, Brasil.

${ }^{3}$ Autor para correspondência: deboracavalcantif@hotmail.com
} 
neste caso com 3 sépalas externas (2 superiores e 1 inferior) e duas internas maiores petalóides, a corola é gamopétala, subactinomorfa, nitidamente pentâmera ou dialipétala, zigomorfa, pentâmera com duas pétalas rudimentares, duas pétalas laterais internas desenvolvidas e uma carena central cuculada cobrindo os órgãos reprodutores ou trímera (sem as duas pétalas rudimentares), os estames são epipétalos ou apresentam filetes unidos em bainha aberta, o ovário é súpero com um único óvulo por lóculo e os frutos são cápsulas, bagas, núculas ou sâmaras (Marques \& Gomes 2002). O reconhecimento das espécies de Polygalaceae muitas vezes é dificultado pela morfologia diferenciada das flores e variação fenotípica das estruturadas vegetativas como o hábito e as folhas (Ferreira \& Alves 2015).

Algumas espécies da família, como Diclidanthera laurifolia Mart. e Moutabea guianensis Aubl. possuem frutos como polpa adocicada e comestível (Souza \& Lorenzi 2008). Outras espécies são de interesse farmacológico, como Polygala paniculata L., devido às atividades analgésica e antiedematogênica (Nogueira et al. 2005) e Polygala sellowiana A. St.-Hil. \& Moq. (=Polygala sabulosa A.W. Benn.) que tem efeito antinociceptivo (Ribas et al. 2008). Estudos fitoquímicos na família demonstram a presença de metabólitos secundários como: xantonas (Cristiano et al. 2003) e cumarinas (Pizzolatti et al. 2002).

Importantes estudos taxonômicos foram realizados com a família, como a Flora Brasiliensis (Bennett 1874) e a Flora da Guiana Venezuelana (Aymard et al. 2004), e floras locais de diferentes estados brasileiros como Paraíba (Coelho et al. 2008), Sergipe (Ferreira \& Alves 2015), Bahia (Marques 1995), Roraima (Costa et al. 2012), Distrito Federal (Pastore \& Cavalcanti 2006), Rio de Janeiro (Marques 1979), São Paulo (Marques \& Gomes 2002), Santa Catarina, Paraná e Rio Grande do Sul (Wurdack \& Smith 1971; Lüdtke et al. 2008a; Lüdtke et al. 2008b; Lüdtke et al. 2013). Além de revisões e sinopses taxonômicas de alguns gêneros como Acanthocladus (Marques 1984a; Pastore et al. 2010), Asemeia (Aguiar et al. 2008), Bredemeyera (Marques 1980), Caamembeca (Marques \& Peixoto 2007), Gymnospora (Marques 1984b; Pastore \& Moraes 2013), Monnina (Marques 1989), Polygala (Marques 1988) e Securidaca (Marques 1996).

Este trabalho faz parte da série de monografias taxonômicas realizadas na Usina São José, Pernambuco (Alves-Araújo \& Alves 2010; Melo et al. 2010; Pontes et al. 2010; Buril \& Alves 2011;
Amorim \& Alves 2011; Pessoa \& Alves 2012; Santos \& Alves 2012; Gomes-Costa \& Alves 2012; Buril et al. 2014; Maciel \& Alves 2014; CostaLima \& Alves 2015) e contribui para o melhor conhecimento da família na porção setentrional da Mata Atlântica situada no Nordeste do Brasil.

\section{Materiais e Métodos}

A Usina São José localiza-se no município de Igarassu, Pernambuco (7040'21,25"-7055'50,92'S e $34^{\circ} 54^{\prime} 14,25^{\prime \prime}-35^{\circ} 05^{\prime} 21,08^{\prime \prime} \mathrm{W}$ ) e compreende uma área total de $280 \mathrm{~km}^{2}$ em aproximadamente 100 fragmentos florestais de Floresta Atlântica, sendo nove deles selecionados para este estudo (Araújo \& Alves 2010). Segundo a classificação de Veloso et al. (1991), a formação vegetal encontrada na área é Floresta estacional semidecidual das terras baixas.

As coletas foram realizadas entre 2007 e 2012, em fragmentos que variam de 30 a 400 ha. Foram ainda agregadas informações obtidas a partir das coleções depositadas nos herbários IPA, PEUFR, HST, UFP e SFP (siglas de acordo com Thiers (continuamente atualizado)). As amostras botânicas foram processadas de acordo com as técnicas usuais em taxonomia vegetal (Mori et al. 1985) e depositadas nos Herbários IPA e UFP. As identificações foram realizadas com auxílio de bibliografia específica (Aguiar et. al. 2008; Aymard et. al. 2004; Coelho et. al. 2008; Marques 1996; Marques \& Gomes 2002) e comparação com amostras previamente identificadas por especialistas, incluindo material-tipo quando disponível. A caracterização morfológica seguiu Gonçalves \& Lorenzi (2007).

O presente trabalho adota a organização empregada para as famílias monografadas anteriormente para a área: Sapotaceae (AlvesAraújo \& Alves 2010), Burmanniaceae e Gentianaceae (Melo et al. 2010), Araceae (Pontes et al. 2010), Convolvulaceae (Buril \& Alves 2011), Myrtaceae (Amorim \& Alves 2011), Orchidaceae (Pessoa \& Alves 2012), Lauraceae (Santos \& Alves 2012), Curcubitaceae (Gomes-Costa \& Alves 2012), Rutaceae, Simaroubaceae, Picramniaceae (Buril et al. 2014), Poaceae (Maciel \& Alves 2014) e Erythroxylaceae (Costa-Lima \& Alves 2015).

\section{Resultados e Discussão}

Nove espécies, distribuídas em cinco gêneros de Polygalaceae, foram registradas na Usina São José, sendo Polygala (4 espécies) o mais representativo em número de espécies. As espécies 
da área são diferenciadas principalmente pelo hábito, ocorrência e formato de glândulas na base do pecíolo e do pedicelo, ápice da carena, tipo de fruto, formato das sementes e ocorrência de apêndices nas mesmas. O registro de Diclidanthera laurifolia Mart. na Usina São José representa a única citação para o estado de Pernambuco (GarcíaGonzález 2011). Nenhuma das espécies da área é indicada como ameaçada de extinção por Martinelli et al. (2013).

\section{Tratamento Taxonômico}

\section{Chave de identificação para as espécies de Polygalaceae da Usina São José}

1. Ervas ou subarbustos.

2. Sépalas externas glabras; carena com o ápice cristado; estilete ereto; carúncula com apêndices membranáceos ou ausentes.

3. Sementes cônicas; inflorescência densiflora.

4. Sementes apendiculadas; brácteas e bractéolas persistentes no fruto

6. Polygala longicaulis

4'. Sementes com 2 apêndices na carúncula; brácteas e bractéolas caducas no fruto

3'. Sementes cilíndricas ou elipsóides; inflorescência laxiflora.

8. Polygala trichosperma

5. Folhas estreito-elípticas em toda a planta; caule cilíndrico, piloso, tricomas claviformes; sementes cilíndricas

7. Polygala paniculata

5'. Folhas lineares, elípticas na base da planta; caule anguloso, glabro; sementes elipsóides 5. Polygala galioides

2'. Sépalas externas com tricomas simples e glandulares; carena com o ápice emarginado; estilete curvo $90^{\circ}$; carúncula com apêndices córneos.

6. Folhas lineares a lanceoladas; pedicelo pubescente com tricomas recurvados

6'. Folhas elípticas, ovadas ou obovadas; pedicelo glabro.

2. Asemeia violacea

1. Asemeia martiana

1'. Arbustos escandentes ou eretos, lianas ou ocasionalmente arvoretas.

7. Presença de glândulas na base do pecíolo (em geral caducas nos ramos adultos) e do pedicelo; inflorescência racemosa; fruto baga ou sâmara.

8. Glândulas crateriformes na base do pecíolo e do pedicelo; flores papilionadas; fruto sâmara

8'. Glândulas globóides na base do pecíolo e do pedicelo; flores tubulares; fruto baga...... 9. Securidaca diversifolia 4. Diclidanthera laurifolia

7'. Ausência de glândulas na base do pecíolo e do pedicelo; inflorescência em panícula; fruto cápsula loculicida......

3. Bredemeyera laurifolia

Asemeia Raf. emend. Small

Subarbustos; raízes geralmente aromáticas. Caules cilíndricos, pubescentes. Folhas alternas, elípticas, ovadas, obovadas ou lineares a lanceoladas, ápice agudo, cuspidado, obtuso ou arredondado; pecíolos sem glândulas na base. Inflorescência racemosa, laxiflora; bráctea central-1, bractéolas laterais-2, diminutas, caducas no fruto; pedicelo sem glândulas na base, glabro ou pubescente. Flores papilionadas, róseas a lilases. Sépalas-5, bisseriadas; sépalas externas-3, com tricomas simples e glandulares, inferior-1, livre, elíptica, superiores-2, parcialmente soldadas, elípticas; sépalas internas-2, obovadas a suborbiculares. Pétalas-3, dialipétalas, laterais-2, espatuladas, carena central cuculada-1, ápice emarginado. Estames-8, filetes unidos em bainha aberta, bainha estaminal glabra ou com base pubescente; anteras oblongas a obovadas. Ovário bicarpelar, estilete curvo a $90^{\circ}$, com tricomas em forma de "U" anterior ao estigma, sem cavidade pré-estigmática, estigma globoso, terminal. Fruto cápsula loculicida, elipsóide; sementes-2, cilíndricas, adpressoseríceas, carúncula com apêndices córneos, laterais-2, dorsal-1. 
1. Asemeia martiana (A.W.Benn.) J.F.B. Pastore \& J.R. Abbott, Kew Bull. 67(4): 8. 2012.

Figs. 1a-c; 3a

Subarbustos, 20,5-52 cm alt. Folhas 1,2-5,6 $\times 0,8-2,3 \mathrm{~cm}$, elípticas, ovadas ou obovadas, ápice agudo, cuspidado, obtuso ou arredondado; pecíolo 1,5-2 mm compr. Inflorescências 1-9 × 1-1,8 cm; raque $0,5-4,5 \mathrm{~cm}$ compr.; bráctea $1-1,2 \times 0,3-0,4$ $\mathrm{mm}$; bractéolas $0,2-0,3 \times 0,05-0,1 \mathrm{~mm}$; pedicelo $1-2,1 \mathrm{~mm}$ compr., glabro. Flores $3-4,3 \times 2-3,1$ $\mathrm{mm}$; sépala externa inferior $1,8-2,2 \times 0,6-0,8 \mathrm{~mm}$; sépalas externas superiores $1,8-2,1 \mathrm{~mm}$ compr., concrescidas, ca. 1-1,2 mm larg.; sépalas internas $2,6-4,3 \times 2-3 \mathrm{~mm}$; pétalas laterais $2,2-3,8 \times 1-1,1$ $\mathrm{mm}$; carena 3,5-4,5 mm compr., cúculo 1,3-2 $\mathrm{mm}$ larg. Bainha estaminal ca. 1,7-3 mm compr., base pubescente. Ovário 1,2-1,3 × 1,1-1,8 mm. Frutos $2,5-5 \times 1,8-3,2 \mathrm{~mm}$; sementes $3,5-3,8 \times 1-1,1 \mathrm{~mm}$. Material examinado: Mata de Piedade, 21.VII.2010, fl. e fr., D. Cavalcanti et al. 215 (UFP); Mata de Vespas, 18.VI.2007, fl. e fr., P.Y. Ojima 63 (UFP); Mata de Pezinho, 9.IV.2009, fl. e fr., E. Pessoa et al. 91 (UFP).

É endêmica do Brasil, sendo encontrada nas regiões Norte e Nordeste, onde ocorre em áreas de Caatinga e Mata Atlântica (BFG 2015). Na Usina São José, foi encontrada em borda de mata. Junto com Asemeia violacea (Aubl.) J.F.B. Pastore \& J.R. Abbott, apresenta sépalas externas com tricomas simples e glandulares, porém diferencia-se por apresentar folhas elípticas, ovadas ou obovadas e pedicelo glabro.

2. Asemeia violacea (Aubl.) J.F.B. Pastore \& J.R. Abbott, Kew Bull. 67(4): 11. 2012.

Figs. 1d-f; 3b

Subarbustos, $19-30 \mathrm{~cm}$ alt. Folhas $1-4,4 \times$ $0,1-0,3 \mathrm{~cm}$, lineares a lanceoladas, ápice agudo; pecíolo $0,5-1,5 \mathrm{~mm}$ compr. Inflorescências $0,4-18$ $\times 0,7-0,8 \mathrm{~cm}$; raque $0,4-18 \mathrm{~cm}$ compr.; bráctea $0,4-1,1 \times 0,3-0,4 \mathrm{~mm}$; bractéolas $0,3-0,4 \times<0,1$ $\mathrm{mm}$; pedicelo $0,1-2 \mathrm{~mm}$ compr., pubescente, com tricomas recurvados. Flores $2,7-4 \times 2,2-3$ $\mathrm{mm}$; sépala externa inferior $2-2,2 \times 0,9-1,8 \mathrm{~mm}$; sépalas externas superiores 1,9-2,1 mm compr., concrescidas, ca. 1,1-1,2 mm larg.; sépalas internas $1,5-4,3 \times 2,1-3,8 \mathrm{~mm}$; pétalas laterais $1,8-3,8 \times$ 1,1-1,4 mm; carena 2,7-2,8 mm compr., cúculo $1,2-1,4 \mathrm{~mm}$ larg. Bainha estaminal ca. $2-2,2 \mathrm{~mm}$ compr., glabra. Ovário $0,5-1 \times 0,4-0,8 \mathrm{~mm}$. Frutos 2,4-4 × 1,7-2,5 mm; sementes $2-3 \times 0,4-1 \mathrm{~mm}$. Material examinado: Mata de Zambana, 18.X.2007, $A$. Alves-Araújo et al. 624 (UFP).

Material adicional: Goiana, RPPN Fazenda Tabatinga, 28.XII.2010, fl. e fr., D. Cavalcanti et al. 365 (UFP).
Ocorre no México, Cuba, Guiana Francesa, Guiana, Equador, Bolívia e Brasil (Aguiar et al. 2008), onde está presente em todas as regiões, em áreas de Caatinga, Cerrado, Mata Atlântica e Floresta Amazônica (BFG 2015). Na Usina São José, foi encontrada em borda de mata. Junto com Asemeia martiana apresenta sépalas externas com tricomas simples e glandulares, porém, diferenciase pelas folhas lineares a lanceoladas e pedicelo pubescente.

\section{Bredemeyera Willd.}

Arbustos escandentes. Ramos cilíndricos, pubescentes. Folhas alternas, elípticas, obovadas a suborbiculares, ápice arredondado, agudo a cuspidado; pecíolos sem glândulas na base. Inflorescência em panícula, densiflora; bráctea central-1, bractéolas laterais-2, persistentes no fruto; pedicelo sem glândulas na base, glabro. Flores papilionadas, alvas a esverdeadas. Sépalas-5, bisseriadas; externas-3, com tricomas simples, inferior-1, livre, elíptica, superiores-2, livres, ovadas; sépalas internas-2, obovadas. Pétalas-5, dialipétalas, rudimentares-2, laterais-2, espatuladas, carena central cuculada-1, ápice emarginado. Estames-8, filetes unidos em bainha aberta, bainha estaminal com ápice pubescente; anteras oblongas, estreitadas na região mediana. Ovário bicarpelar, estilete curvo a $90^{\circ}$, glabro, sem cavidade pré-estigmática, estigma bilobado, terminal. Fruto cápsula loculicida, obovado; sementes-2, cilíndricas, tomentosas, com tufo de tricomas longos, carúncula galeada.

3. Bredemeyera laurifolia (A.St.-Hil. \& Moq.) Klotzsch ex A.W. Benn, Bennett in Mart., Fl. bras. 13(3): $52.1874 . \quad$ Figs. 1g-1; 3c-e

Folhas 1-8 × 0,5-3 cm; pecíolo $1-5 \mathrm{~mm}$ compr. Inflorescências 4,5-14,4 × 15-17 cm; raque 4,5-14 cm compr.; bráctea $0,9-1,5 \times 0,5-0,8$ $\mathrm{mm}$; bractéolas $0,7-1 \times 0,5-0,6 \mathrm{~mm}$; pedicelo $0,3-0,5 \mathrm{~mm}$ compr. Flores $3-5 \times 1,8-2,8 \mathrm{~mm}$; sépala externa inferior $1,8-2,5 \times 1,2-1,4 \mathrm{~mm}$; sépalas externas superiores 1,7-2,2 × 1,3-1,4 mm; sépalas internas $3,2-4,2 \times 2,3-2,8 \mathrm{~mm}$; pétalas rudimentares $0,3 \times 0,3 \mathrm{~mm}$; pétalas laterais $2,3-4$ $\times 1,2-1,8 \mathrm{~mm}$; carena 3,3-4 mm compr., cúculo 1,7-2,2 mm larg. Bainha estaminal ca. 2,4 mm compr. Ovário $0,9-1,1 \times 0,4-0,5 \mathrm{~mm}$. Frutos $5-12$ $\times 2-5 \mathrm{~mm}$; sementes 5-7 × 1,2-2 mm.

Material examinado: Mata do Pezinho, 2.III.2009, f1., A. Melo et al. 350 (UFP); Mata Santa Helena, 11.IX.2007, fl., A. Melo et al. 35 (UFP); Mata de Chave, 18.XII.2009, fr., D. Cavalcanti et al. 39 (UFP). 

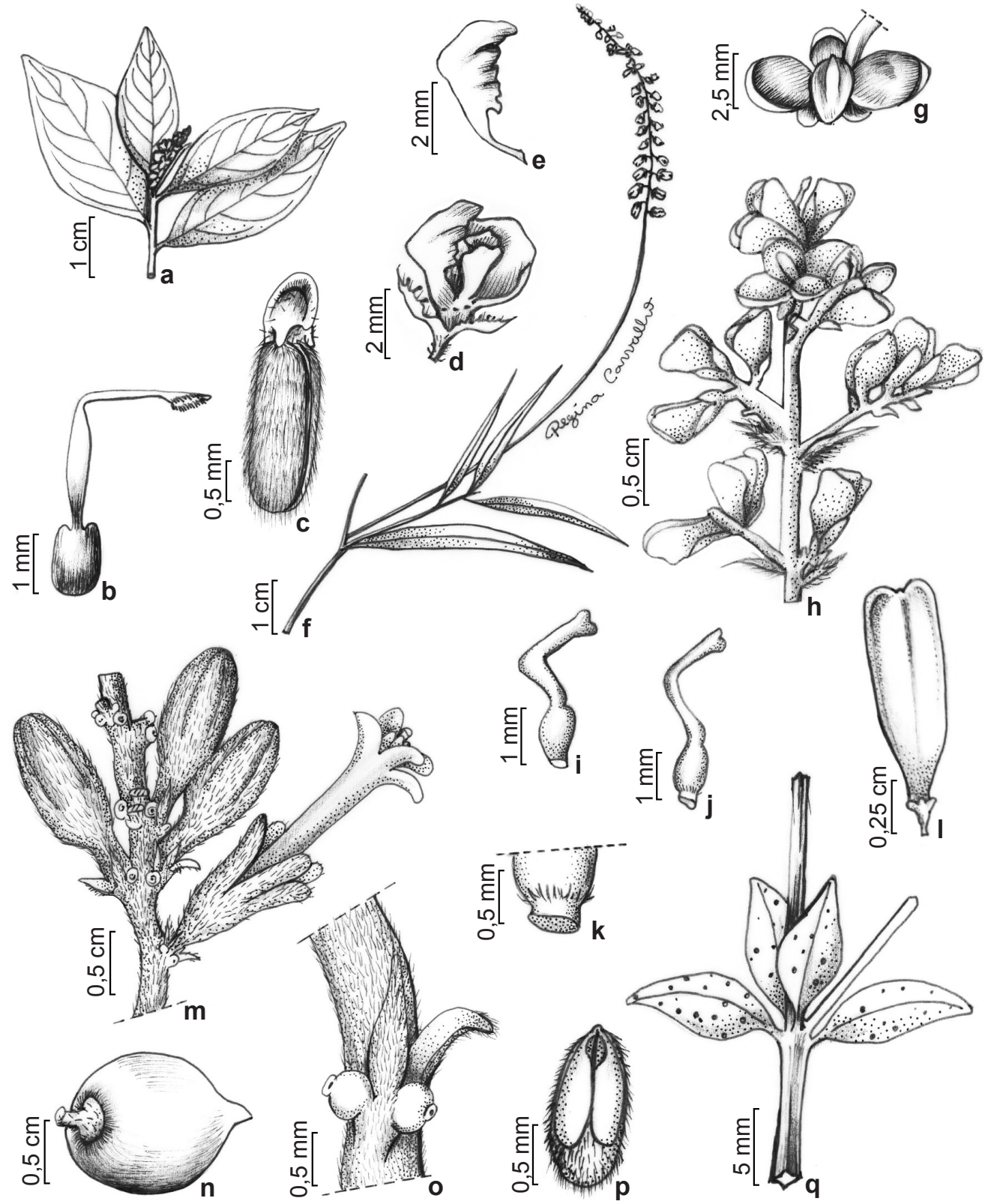

Figura 1 - a-c. Asemeia martiana - a. folhas; b. estilete curvo formando ângulo de $90^{\circ}$; c. semente com carúncula com apêndices córneos. d-f. Asemeia violacea - d. flor; e. carena com o ápice emarginado; f. hábito. g-1. Bredemeyera laurifolia - g. flor; h. inflorescência; i. ovário sem anel de tricoma na base; j. ovário com anel de tricoma na base; k. detalhe do anel de tricoma na base do ovário; 1 . fruto. m-o. Diclidanthera laurifolia - m. inflorescência; $n$. fruto; o. glândulas globóides na base do pedicelo. p-q. Polygala galioides - p. semente com carúncula com apêndices membranáceos; q. caule anguloso, glabro. (a-c. D. Cavalcanti 215; d-f. D. Cavalcanti 365; g. D. Cavalcanti 487; h. A. Melo 35; i. A. Melo 350; j-k. A. Melo 35; 1. D. Cavalcanti 39; m. C. Farney 4138; n-o. J.A. Lombardi 6995; p-q. A. Alves-Araújo 1066).

Figure 1 - a-c. Asemeia martiana - a. leaves; b. curved style forming an angle of $90^{\circ}$; c. seed with caruncle with corneous appendages. d-f. Asemeia violacea - d. flower; e. carina with emarginated apex (keeled); f. habit. g-1. Bredemeyera laurifolia - g. flower; h. inflorescence; i. ovary without the basal ring of trichomes; $\mathrm{j}$. ovary with the basal ring of trichomes; $\mathrm{k}$. detail of the ring of trichomes on the base of the ovary; 1 . fruit. m-o. Diclidanthera laurifolia $-\mathrm{m}$. inflorescence; $\mathrm{n}$. fruit; o. globoid glands on the base of the pedicel. $\mathrm{p}$-q. Polygala galioides - p. seed with caruncle with membranaceous appendages; q. angular stem, glabrous. (a-c. D. Cavalcanti 215; d-f. D. Cavalcanti 365; g. D. Cavalcanti 487; h. A. Melo 35; i. A. Melo 350; j-k. A. Melo 35; 1. D. Cavalcanti 39; m. C. Farney 4138; n-o. J.A. Lombardi 6995; p-q. A. Alves-Araújo 1066). 
Endêmica do Brasil, ocorrendo em todas as regiões, em áreas de Caatinga, Mata Atlântica, Cerrado e Floresta Amazônica (BFG 2015). Na Usina São José foi encontrada em borda de mata. É diferenciada das demais espécies da área por apresentar inflorescências em panículas. Com base nas amostras, confirma-se que o anel de tricomas na base do ovário pode estar ausente na espécie, como sugerido por Pastore (2010) para Bredemeyera hebeclada (DC.) J.F.B.Pastore.

\section{Diclidanthera Mart.}

Lianas a ocasionalmente arbustos ou arvoretas. Ramos cilíndricos, pilosos. Folhas alternas, elípticas a obovadas, ápice agudo; pecíolos com 2 glândulas na base, glândulas globóides proximais, por vezes caducas. Inflorescência racemosa, densiflora; bráctea central-1, bractéolas laterais-2, caducas no fruto; pedicelo com 2 glandulas na base, glândulas globóides, piloso. Flores tubulares, cremes. Sépalas-5, unisseriadas, com tricomas simples, concrescidas, lobos oblongos. Pétalas-5, gamopétalas, corola hipocrateriforme, lobos oblongos. Estames-8, epipétalos; anteras oblongas. Ovário 5-carpelar, estilete ereto, piloso, sem cavidade pré-estigmática, estigma capitado, terminal. Fruto baga, globoso; sementes-1-3, elipsóides a ovóides, pubescentes, apendiculadas.

4. Diclidanthera laurifolia Mart., Nov. gen. sp. 2 (2): 141.1826.

Figs. $1 \mathrm{~m}-\mathrm{o} ; 3 \mathrm{f}$

Folhas 1,5-12,5 × 0,7-4,6 cm; pecíolo 2-9 $\mathrm{mm}$ compr. Inflorescências 0,7-3,6 × 0,9-1,2 cm; raque $0,7-2,5 \mathrm{~cm}$ compr.; bráctea $1,4-1,5 \times 0,3 \mathrm{~mm}$; bractéolas 1,3 $\times 0,4 \mathrm{~mm}$; pedicelo $2-4 \mathrm{~mm}$ compr. Flores 6,2-16,5 mm compr.; cálice 5,9-7,5 mm compr., tubo 1,5-2,5 mm compr., lobos 4,4-5 mm compr.; corola $6,2-16,5 \mathrm{~mm}$ compr., lobos $2,8-4,2$ $\mathrm{mm}$ compr. Ovário $1-1,5 \times 0,7-1,3 \mathrm{~mm}$. Frutos 4-16 × 4-16 mm; sementes 8,5-10 × 4,5-8,5 mm. Material examinado: Mata de Piedade, 28.I.2010, J.D. García 1405 (UFP).

Material adicional: BRASIL. RIO DE JANEIRO: São Pedro da Aldeia, fl., 24.VIII.2000, C. Farney 4138 (SPF); SÃO PAULO: Jundiaí, 23.X.2007, fr., J.A. Lombardi 6995 (SPF).

Endêmica do Brasil, onde ocorre nas regiões Nordeste e Sudeste em áreas de Cerrado e Mata Atlântica (BFG 2015). Na Usina São José, foi encontrada no interior da mata. Vegetativamente pode ser reconhecida pela organização dos feixes vasculares no corte transversal do caule e pelas glândulas globóides na base do pecíolo e do pedicelo (García-González 2011). Assemelha-se com Securidaca diversifolia (L.) S.F.Blake pelo hábito que pode ser liana a ocasionalmente arbusto ou arvoreta, e pela presença de glândulas na base do pecíolo e do pedicelo, porém diferencia-se, por apresentar glândulas do tipo globóides na base do pecíolo e do pedicelo e flores tubulares.

\section{Polygala L.}

Ervas ou subarbustos; raízes geralmente aromáticas. Caules angulosos ou cilíndricos, glabros ou pilosos, com tricomas claviformes. Folhas completamente alternas, ou no ápice alternas e na base da planta verticiladas, ou alternas e verticiladas, estreito-elípticas, lineares, ou lineares no ápice e elípticas na base da planta ou lineares no ápice e obovadas na base da planta, ápice agudo, cuspidado a agudo ou mucronado; sésseis. Inflorescência racemosa, densiflora ou laxiflora; bráctea central-1, bractéolas laterais-2, diminutas, caducas ou persistentes no fruto; pedicelo sem glândulas na base, glabro ou pubérulo a glabro. Flores papilionadas, róseas ou alvas. Sépalas-5, bisseriadas; sépalas externas-3, glabras, inferior-1, livre, elíptica, superiores-2, livres, elípticas; sépalas internas-2, obovadas, estreito-elípticas ou elípticas. Pétalas-3, dialipétalas, laterais-2, elípticas, estreito-elípticas ou oblanceoladas, carena central cuculada-1, ápice cristado. Estames-8, filetes unidos em bainha aberta, bainha estaminal glabra; anteras oblongas ou obovadas. Ovário bicarpelar, estilete ereto, terminado por uma cavidade pré-estigmática, cavidade pré-estigmática com um tufo de tricomas no ápice, estigma globoso, situado na extremidade inferior da cavidade préestigmática. Fruto cápsula loculicida, elipsoide ou ovóide; sementes-2, elipsóides, cônicas ou cilíndricas, pubescentes, carúncula com apêndices membranáceos-2, presentes ou ausentes.

5. Polygala galioides Poir. in Lam., Encycl. 5: 503. 1804.

Figs. 1p-q; $3 \mathrm{~g}$

Ervas, $14-27,5 \mathrm{~cm}$ alt. Caule anguloso, glabro. Folhas $0,2-1,2 \times 0,1-0,5 \mathrm{~cm}$, alternas e lineares no ápice da planta e verticiladas e elípticas na base da planta, ápice agudo. Inflorescências $0,5-18,4 \times$ $0,2-0,5 \mathrm{~cm}$, laxifloras; raque $0,4-16,2 \mathrm{~cm}$ compr.; bráctea $1-1,1 \times 0,2-0,3 \mathrm{~mm}$, caduca no fruto; bractéolas $0,2-0,3 \times 0,1 \mathrm{~mm}$, caducas no fruto; pedicelo $0,1-0,7 \mathrm{~mm}$ compr., pubérulo a glabro. Flores 1,2-2,2 $\times 0,8-1,3 \mathrm{~mm}$, róseas; sépala externa inferior $1-1,5 \times 0,3-0,5 \mathrm{~mm}$; sépalas externas superiores $0,7-0,8 \times 0,3-0,4 \mathrm{~mm}$; sépalas internas 
1,2-2 × 0,6-1 mm, obovadas; pétalas laterais 1,2-2

$\times 0,3-0,5 \mathrm{~mm}$, estreito-elípticas; carena 1,1-2 $\mathrm{mm}$ compr., cristas 5-lobos, cúculo 0,4-0,6 mm larg. Bainha estaminal ca. 0,7 mm compr.; anteras oblongas. Ovário $0,3-0,8 \times 0,3-0,5 \mathrm{~mm}$. Frutos $1-1,7 \times 0,6-1,2 \mathrm{~mm}$, elipsóides; sementes $1-1,3$ $\times 0,3-0,4 \mathrm{~mm}$, elipsóides, apêndices da carúncula $0,7-0,8 \mathrm{~mm}$ compr.

Material examinado: Mata de Piedade, 21.VIII.2010, fl. e fr., D. Cavalcanti et al. 214 (UFP); Mata de Piedade, 10.IX.2008, fl. e fr., A. Alves-Araújo et al. 1066 (UFP). Material adicional: BRASIL. PIAUÍ: Cocal das Telhas, 28.IV.2006, fl. e fr., A. Alves-Araújo et al. 144 (UFP).

Ocorre na Guiana, Guiana Francesa e no Brasil (Marques 1988), onde ocorre nas regiões Norte, Nordeste, Centro-Oeste e Sudeste, em áreas de Cerrado, Mata Atlântica e Floresta Amazônica (BFG 2015). Na Usina São José, foi encontrada próxima a um açude em uma área aberta. Diferencia-se das demais espécies do gênero da área pelas sementes elipsóides.

6. Polygala longicaulis Kunth in Humb., Bonpl. \& Kunth, Nov. Gen. Sp. 5, ed. 4: 396-397. 1823.

Figs. 2a-d; 3h

Subarbustos, $11-37 \mathrm{~cm}$ alt. Caule anguloso, glabro. Folhas $0,4-1,3 \times 0,05-0,3 \mathrm{~cm}$, alternas e lineares no ápice da planta e verticiladas e obovadas na base da planta, ápice cuspidado a agudo. Inflorescências 3,5-8,1 × 0,1-1 cm, densifloras; raque $0,9-1,5 \mathrm{~cm}$ compr.; bráctea $1-1,7$ $\times 0,5-0,7 \mathrm{~mm}$, persistente no fruto; bractéolas $0,6-0,8 \times 0,3-0,4 \mathrm{~mm}$, persistentes no fruto; pedicelo 1-3 mm compr., glabro. Flores 2,5-5 $\times$ 1-3 mm, róseas; sépala externa inferior, $1,5-1,6$ $\times 0,9-1 \mathrm{~mm}$; sépalas externas superiores $1-1,3$ $\times 0,3-0,4 \mathrm{~mm}$; sépalas internas $2-5 \times 1-2,5 \mathrm{~mm}$, estreito-elípticas; pétalas laterais $1-4,2 \times 0,3-0,9$ $\mathrm{mm}$, oblanceoladas; carena $3,2-4,8 \mathrm{~mm}$ compr., cristas 4-8-lobos, cúculo 0,4-0,7 mm larg. Bainha estaminal 3,2-3,7 mm compr.; anteras obovadas. Ovário $0,7-1,2 \times 0,3-0,8 \mathrm{~mm}$. Frutos 2,5-3,5 $\times$ 1,5-2 mm, elipsóides; sementes 1,5-1,8 × 0,5-0,7 $\mathrm{mm}$, cônicas, apendiculadas.

Material examinado: Mata de Zambana, 28.VII.2007, fl. e fr., A. Melo et al. 98 (UFP).

Material adicional: BRASIL. SERGIPE: Parque Nacional Serra de Itabaiana, 22.VII.2006, fl. e fr., J.R. Maciel 325 (UFP).

Ocorre desde o México até Paraguai (Aymard et al. 2004). No Brasil ocorre em todas as regiões e domínios fitogeográficos (BFG 2015). Na Usina São José foi encontrada em borda de mata. Assemelha-se a Polygala trichosperma Jacq., por apresentar sementes cônicas e inflorescências densifloras, porém diferencia-se por apresentar bráctea e bractéolas persistentes no fruto e sementes apendiculadas.

7. Polygala paniculata L., Syst. nat. 2: 1154. 1759. Figs. 2e-g; $3 \mathrm{i}$

Subarbustos, $10-60 \mathrm{~cm}$ alt. Caule cilíndrico, piloso, tricomas claviformes. Folhas $0,2-2,7 \times$ $0,05-0,35 \mathrm{~cm}$, alternas e verticiladas, estreitoelípticas, ápice mucronado. Inflorescências $0,5-11 \times 0,2-0,7 \mathrm{~cm}$, laxifloras; raque $0,4-10 \mathrm{~cm}$ compr.; bráctea $0,8-1 \times 0,2-0,3 \mathrm{~mm}$, caduca no fruto; bractéolas $0,2-0,6 \times 0,1-0,2 \mathrm{~mm}$, caducas no fruto; pedicelo $0,2-1,4 \mathrm{~mm}$ compr., glabro. Flores 1,1-2,5 × 0,7-1,3 mm, alvas; sépala externa inferior 1,1-1,2 × 0,5-0,6 mm; sépalas externas superiores $1-1,1 \times 0,3-0,4 \mathrm{~mm}$; sépalas internas $1-2 \times 0,5-0,6 \mathrm{~mm}$, elípticas; pétalas laterais $2-2,6$ $\times 0,4-0,7 \mathrm{~mm}$, elípticas; carena $1-2,2 \mathrm{~mm}$ compr., cristas 4-lobos, cúculo 0,4-0,7 mm larg. Bainha estaminal 1-1,2 mm compr.; anteras obovadas. Ovário $0,4-0,7 \times 0,2-0,4 \mathrm{~mm}$. Frutos $1,5-2,5$ $\times 0,8-1,1 \mathrm{~mm}$, elipsóides; sementes 1,2-1,9 × $0,3-0,5 \mathrm{~mm}$, cilíndricas, apêndices da carúncula $0,8-1 \mathrm{~mm}$ compr.

Material examinado: Mata de Piedade, 21.VIII.2010, fl. e fr., D. Cavalcanti 216 (UFP); Mata dos Macacos, 19.VI.2007, fl. e fr., P.Y. Ojima 67 (UFP).

De acordo com Marques (1988), é uma espécie com distribuição neotropical. No Brasil há registros para todas as regiões ocorrendo em todos os domínios fitogeográficos (BFG 2015). $\mathrm{Na}$ Usina São José, foi encontrada em borda de mata e locais sazonalmente alagados. É diferenciada das demais espécies da área pelos tricomas claviformes presentes no caule.

8. Polygala trichosperma Jacq., Jacq., Observ. Bot. 3: 16.1768. Figs. $2 \mathrm{~h} ; 3 \mathrm{j}$

Subarbustos, $31-38 \mathrm{~cm}$ alt. Caule anguloso, glabro. Folhas $0,1-1,2 \times 0,05-0,1 \mathrm{~cm}$, alternas, lineares, ápice agudo. Inflorescências $0,5-2,5 \times$ $0,5-0,8 \mathrm{~cm}$, densifloras; raque $0,3-1,5 \mathrm{~cm}$ compr.; bráctea $0,6-0,8 \times 0,2-0,4 \mathrm{~mm}$, caduca no fruto; bractéolas $0,4-0,6 \times 0,1-0,2 \mathrm{~mm}$, caducas no fruto; pedicelo $0,1-1 \mathrm{~mm}$ compr., glabro. Flores $2-4,2 \times 1,6-1,7 \mathrm{~mm}$, róseas; sépala externa inferior $1,3-1,6 \times 0,8-0,9 \mathrm{~mm}$; sépalas externas superiores $0,8-1,3 \times 0,3-0,4 \mathrm{~mm}$; sépalas internas $2-4,2 \times$ $0,9-1,7 \mathrm{~mm}$, obovadas; pétalas laterais $1-3,8 \times$ 0,3-1,2 mm, oblanceoladas; carena 2,3-3,5 mm compr., cristas 4-lobos, cúculo 0,7-0,9 mm larg. 

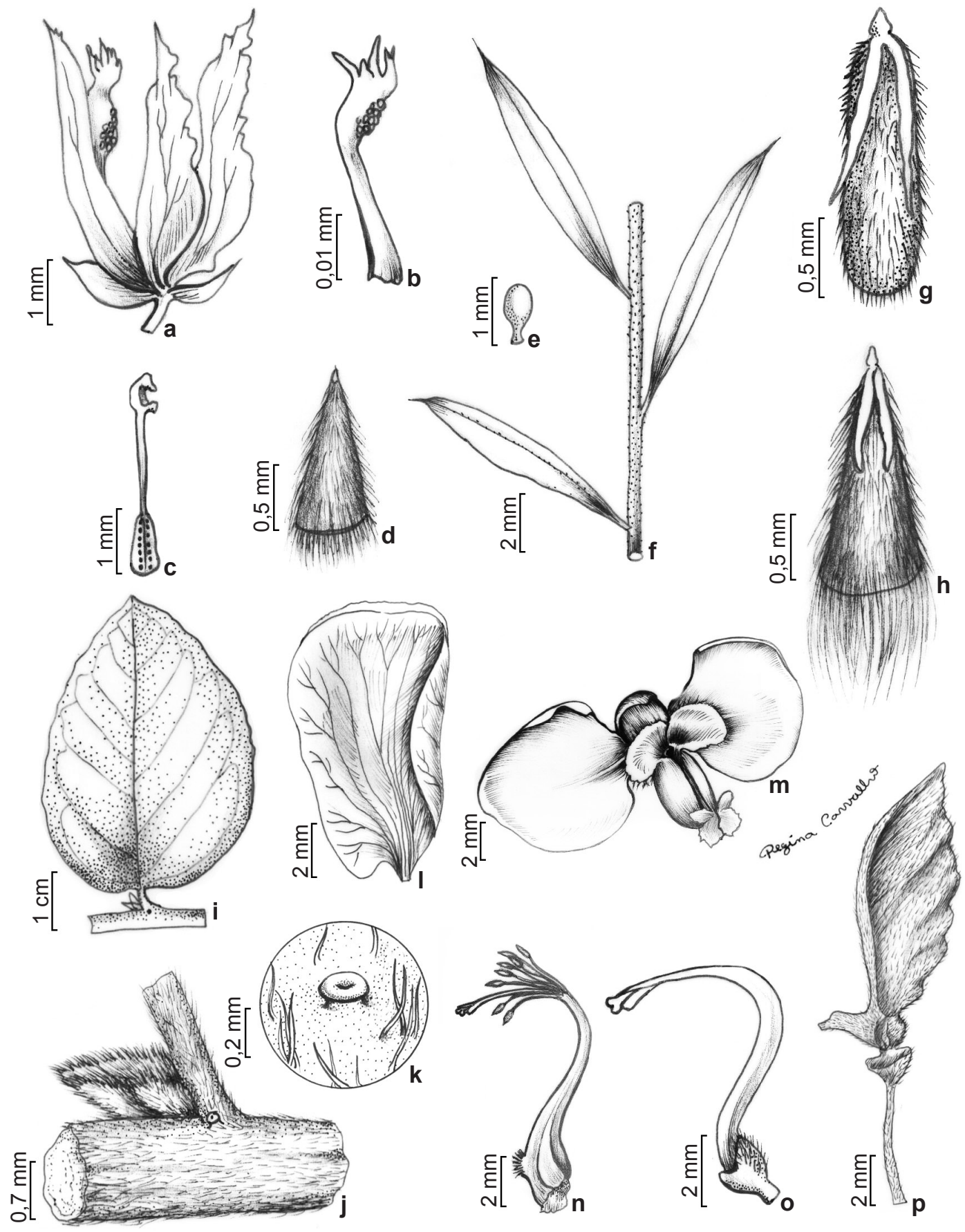

Figura 2 - a-d. Polygala longicaulis - a. flor; b. carena com o ápice cristado; c. estilete ereto; d. semente sem apêndices. e-g. Polygala paniculata - e. tricoma claviforme; f. caule cilíndrico; g. semente com dois apêndices. h. Polygala trichosperma semente com dois apêndices. i-p. Securidaca diversifolia - i. folha; j. glândula crateriforme na base do pecíolo; k. detalhe da glândula crateriforme; 1 . sépala interna; $\mathrm{m}$. flor; $\mathrm{n}$. androceu e gineceu; o. gineceu; p. fruto. (a-d. A. Melo 98; e-g. D. Cavalcanti 216; h. A. Melo 118; i-k. Alves-Araújo 728; 1-p. N.A. Albuquerque 586).

Figure 2 - a-d. Polygala longicaulis - a. flower; b. carina with the cristate apex (keeled); c. upright style; d. seed without appendages. e-g. Polygala paniculata - e. clavete trichome; f. cylindrical stem; g. seed with two appendages. h. Polygala trichosperma - seed with two appendages. i-p. Securidaca diversifolia $-\mathrm{i}$. leaf; $\mathrm{j}$. crateriform glands at the base of the petiole; $\mathrm{k}$. detail of the crateriform glands; 1 inner sepal; $\mathrm{m}$. flower; $\mathrm{n}$. androecium and gynoecium; o. gynoecium; p. fruit. (a-d. A. Melo 98; e-g. D. Cavalcanti 216; h. A. Melo 118; i-k. Alves-Araújo 728; 1-p. N.A. Albuquerque 586). 

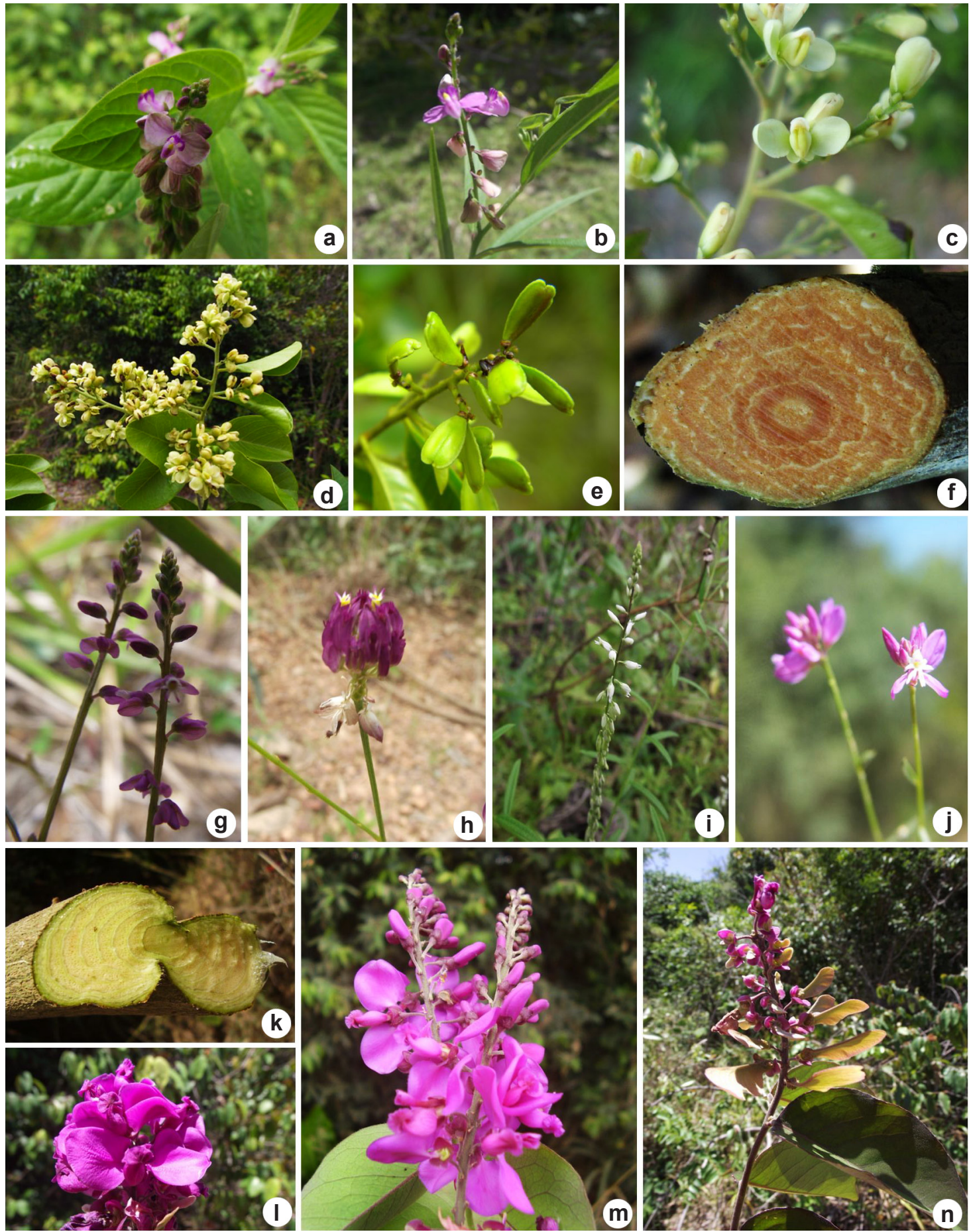

Figura 3 - a. Asemeia martiana - inflorescência. b. Asemeia violacea - inflorescência. c-e. Bredemeyera laurifolia - c. flor; d. inflorescência; e. frutos. f. Diclidanthera laurifolia - corte transversal do caule. g. Polygala galioides - inflorescência. h. Polygala longicaulis - inflorescência. i. Polygala paniculata - inflorescência. j. Polygala trichosperma - inflorescências. k-n. Securidaca diversifolia-k. corte transversal do caule; 1 flores; m. inflorescências; n. frutos jovens. (d. B.S.Amorim; f. J.D. García; k,m. D. Araújo). Figure 3 -a. Asemeia martiana-inflorescence. b. Asemeia violacea-inflorescence. c-e. Bredemeyera laurifolia-c. flower; d. inflorescence; e. fruits. f. Diclidanthera laurifolia -cross-section of the stem. g. Polygala galioides-inflorescence. h. Polygala longicaulis - inflorescence. i. Polvgala paniculata - inflorescence. j. Polygala trichosperma - inflorescences. k-n. Securidaca diversifolia - k. cross-section of the stem; 1 . flores; $m$. inflorescences; $n$. immature fruits. (d. B.S. Amorim; f. J.D. García; k,m. D. Araújo). 
Bainha estaminal ca. 0,5-2,4 mm compr.; anteras obovadas. Ovário 0,6-0,8 × 0,3-0,4 mm. Frutos 3,3-3,4 × 1,7-1,8 mm, ovóides; sementes 1,7-2,4 $\times$ 0,4-0,6 mm, cônicas, apêndices da carúncula 0,8-1,1 mm compr.

Material examinado: Mata de Zambana, 4.IX.2007, fl. e fr., A. Melo et al. 118 (UFP).

Material adicional: BRASIL. BAHIA: Santana, 13.III.2010, fl. e fr., K. Yoshida-Arms-BHRG 476 (UFP).

Ocorre no México, América Central, Colômbia, Guiana, Suriname, Guiana Francesa e Brasil (Aymard et. al. 2004), onde está presente nas regiões Norte e Nordeste, em áreas de Caatinga, Cerrado, Mata Atlântica e Floresta Amazônica (BFG 2015). Na Usina São José, foi encontrada em borda de mata. É morfologicamente similar a Polygala longicaulis, por apresentar sementes cônicas e inflorescência densifloras, porém, diferencia-se por apresentar bráctea e bractéolas caducas no fruto e sementes com dois apêndices.

\section{Securidaca L.}

Lianas a ocasionalmente arbustos escandentes a arvoretas. Ramos cilíndricos, pubescentes. Folhas alternas, ovais a elípticas, ápice agudo a emarginado; pecíolos com 2 glândulas na base, glândulas crateriformes. Inflorescência racemosa, densiflora; bráctea central-1, bractéolas laterais-2, caducas no fruto; pedicelo com 2 glândulas na base, glândulas crateriformes, pubescente. Flores papilionadas, róseas. Sépalas-5, bisseriadas; sépalas externas-3, com tricomas simples, inferior-1, livre, ovada, superiores-2, livres, assimétricas a largo-elípticas; sépalas internas-2, obovadas. Pétalas-5, dialipétalas, rudimentares-2, laterais-2, espatuladas, carena central cuculada-1, ápice cristado. Estames-8, filetes unidos em bainha aberta, bainha estaminal com base pubescente; anteras oblongas. Ovário bicarpelar, estilete curvo a $90^{\circ}$, glabro, sem cavidade pré-estigmática, estigma bilobado, terminal. Fruto sâmara; semente-1, elipsóide, glabra, apendiculada.

9. Securidaca diversifolia (L.) S.F. Blake, Contr. U.S. Natl. Herb. 23(3): 594. 1923.

Figs. 2i-p; 3k-n

Folhas 1,1-8,5 × 1,8-4,5 cm; pecíolo 2-5 $\mathrm{mm}$ compr. Inflorescências 4-11 × 0,5-1,4 cm; raque 2,7-10,5 cm compr.; bráctea 1,8-2,4 $\times$ 0,4-0,6 mm; bractéolas $1-1,1 \times 0,2-0,3 \mathrm{~mm}$; pedicelo 4-6 mm compr. Flores 9-13,5 × 6,5-10 $\mathrm{mm}$; sépala externa inferior 4,5-5 × 3,3-3,5 mm; sépalas externas superiores 4-4,5 × 3-3,5 mm; sépalas internas $9-13,5 \times 6,5-10 \mathrm{~mm}$; pétalas rudimentares $0,3-1 \times 0,3-0,4 \mathrm{~mm}$ compr; pétalas laterais 7-10 × 4-4,5 mm; carena 9,2-10 mm compr., cúculo 4,5-5 mm larg. Bainha estaminal ca. $7 \mathrm{~mm}$ compr. Ovário 1,5-1,7 × 1-1,2 mm. Frutos 13-28 × 4,9-6 mm; sementes 2-3,2 $\times$ 1,3-1,8 mm.

Material examinado: Mata dos Macacos, 19.XII.2007, fl., A. Alves-Araújo et al. 728 (UFP); Mata da Zambana, 29.XI.2007, fl. e fr., N.A. Albuquerque et al. 586 (IPA). Material adicional: Goiana, RPPN Fazenda Tabatinga, 29.IX.2010, fl. e fr., D. Cavalcanti et al. 626 (UFP).

Ocorre em todas as regiões do Brasil em áreas de Caatinga, Cerrado, Mata Atlântica e Floresta Amazônica (BFG 2015). Na Usina São José, foi encontrada em borda de mata. É diferenciada das demais espécies da área pelas glândulas crateriformes na base do pecíolo e do pedicelo e pelos frutos do tipo sâmara. Assemelhase com Diclidanthera laurifolia, pelo hábito que pode ser liana a ocasionalmente arbusto ou arvoreta, e pela presença de glândulas na base do pecíolo e do pedicelo, porém diferencia-se, por apresentar glândulas do tipo crateriformes na base do pecíolo e do pedicelo e flores papilonadas.

\section{Agradecimentos}

A primeira autora agradece ao $\mathrm{CNPq}$, a bolsa de Iniciação Científica concedida. Ao CNPq, NSF e Beneficia Foundation, o suporte financeiro. Aos curadores dos herbários visitados, à ilustradora botânica Regina Carvalho, e ao Dr. Floriano Pastore, as discussões taxonômicas e disponibilização de bibliografia.

\section{Referências}

Alves-Araújo, A. \& Alves, M. 2010. Flora da Usina São José, Igarassu, Pernambuco: Sapotaceae. Rodriguésia 61: 303-318.

Aguiar, A.C.A.; Marques, M.C.M. \& Yamamoto, K. 2008. Taxonomia das espécies de Polygala L. subg. Hebeclada (Chodat) Blake (Polygalaceae) ocorrentes no Brasil. Revista Brasileira de Biociências 6: 81-109.

Amorim, B.S. \& Alves, M. 2011. Flora da Usina São José, Igarassu, Pernambuco: Myrtaceae. Rodriguésia 62: 499-514.

APG (Angiosperm Phylogenetic Group) IV. 2016. An update of the angiosperm phylogenetic group classification for the orders and families of flowering plants: APG IV. Botanical Journal of the Linnean Society 181: 1-20.

Araújo, D. \& Alves, M. 2010. Climbing plants of a fragmented area of lowland Atlantic Forest, Igarassu, Pernambuco (northeastern Brazil). Phytotaxa 8: 1-24. 
Aymard, G.A.; Berry, P.E. \& Eriksen, B. 2004. Polygalacaeae. In: Steyermark, J.A.; Berry, P.E.; Yatskievych, K. \& Holst, B.K. (eds.). Flora of the Venezuelan Guayana. Vol. 8. Missouri Botanical Garden Press, Saint Louis. Pp. 316-347.

Bennett, A.W. 1874. Polygalaceae. In: Martius, C.F.P.; Eichler, A. \& Urban, I. (eds.). Flora brasiliensis. F. Fleischer, Leipzig. Vol. 13, pars 3, pp. 1-82.

BFG. 2015. Growing knowledge: an overview of Seed Plant diversity in Brazil. Rodriguésia 66: 1085-1113.

Buril, M.T. \& Alves, M. 2011. Flora da Usina São José, Igarassu, Pernambuco: Convolvulaceae. Rodriguésia 62: 93-105.

Buril, M.T.; Thomas, W.W. \& Alves, M. 2014. Flora da Usina São José, Igarassu, Pernambuco: Rutaceae, Simaroubaceae e Picramniaceae. Rodriguésia 65: 701-710.

Coelho, V.P.M.; Agra, M.F. \& Baracho, G.S. 2008. Flora da Paraíba, Brasil: Polygala L. (Polygalaceae). Acta botanica brasilica 22: 225-239.

Costa-Lima, J.L. \& Alves, M. 2015. Flora da Usina São José, Igarassu, Pernambuco: Erythroxylaceae. Rodriguésia 66: 285-295.

Costa, C.S.; Flores, A.S. \& Rodrigues, R.S. 2012. A família Polygalaceae em uma área de savana em Roraima, Brasil. Revista brasileira de Biociências 10: 468-480.

Cristiano, R.; Pizzolatti, M.G.; Monache, F.D.; Rezende, C.M. \& Branco, A. 2003. Two xanthones from Polygala paniculata and confirmation of the 1-hydroxy-2,3,5-trimethoxy-xanthone at trace level by HRGC-MS. Zeitschrift für Naturforschung 58 : 490-494.

Ferreira, D.M.C. \& Alves, M. 2015. Polygalaceae. In: Prata, A.P.N.; Farias, M.C.V. \& Landim, M.F. (orgs.). Flora de Sergipe. Vol. 2. Criação editora, Aracaju. Pp. 224-242.

Gomes-Costa, G.A. \& Alves, M. 2012. Flora da Usina São José, Igarassu, Pernambuco: Cucurbitaceae. Rodriguésia 63: 817-829.

Gonçalves, E.G. \& Lorenzi, H. 2007. Morfologia vegetal: organografia e dicionário ilustrado de morfologia das plantas vasculares. Instituto Plantarum de Estudos da Flora, Nova Odessa. 416p.

García-González, J.D. 2011. Diversidade e abundância de lianas em uma área de floresta atlântica semidecidual ao norte do estado de Pernambuco. Dissertação de Mestrado. Universidade Federal de Pernambuco, Recife. 103p.

Lüdtke, R.; Souza-Chies, T.T. de \& Miotto, S.T.S. 2008a. Flora ilustrada do Rio Grande do Sul. Bredemeyera Willd. e Securidaca L. (Polygalaceae) na Região Sul do Brasil. Revista Brasileira de Biociências 6: 69-79.

Lüdtke, R. \& Miotto, S.T.S. 2008b. A família Polygalaceae no Parque Estadual de Itapuã,Viamão, Rio Grande do Sul, Brasil. Revista Brasileira de Biociências 6: 245-251.
Lüdtke, R.; Souza-Chies, T.T. \& Miotto, S.T.S. 2013. Polygala na Região Sul do Brasil. Hoehnea 40: $1-50$.

Maciel, J.R. \& Alves, M. 2014. Flora da Usina São José, Igarassu, Pernambuco: Poaceae. Rodriguésia 65: 355-367.

Marques, M.C.M. 1979. Revisão das espécies do gênero Polygala L. (Polygalaceae) do estado do Rio de Janeiro. Rodriguésia 31: 69-339.

Marques, M.C.M. 1980. Revisão das espécies do gênero Bredemeyera Willd. (Polygalaceae) do Brasil. Rodriguésia 32: 269-321.

Marques, M.C.M. 1984a. Polígalas do Brasil I Seção Acanthocladus (K1. Ex Hassk.) Chod. (Polygalaceae). Rodriguésia 36: 3-10.

Marques, M.C.M. 1984b. Polígalas do Brasil-III Seção Gymnospora Chod. do gênero Polygala L. (Polygalaceae). Rodriguésia 36: 31-34.

Marques, M.C.M. 1988. Polígalas do Brasil V - Seção Polygala (Polygalaceae). Arquivos do Jardim Botânico do Rio de Janeiro 29: 1-114.

Marques, M.C.M. 1989. Monnina Ruiz et Pavon (Polygalaceae) no Brasil. Rodriguésia 67: 3-33.

Marques, M.C.M. 1995. Polygalaceae. In: Stannard, B.L. Flora of the Pico das Almas. Chapada Diamantina - Bahia, Brazil. Royal Botanic Gardens, Kew. Pp. 534-541.

Marques, M.C.M. 1996. Securidaca L. (Polygalaceae) do Brasil. Arquivos do Jardim Botânico do Rio Janeiro 34: 7-144.

Marques, M.C.M. \& Gomes, K. 2002. Polygalaceae. In: Wanderley, M.L.; Shepherd, G.J.; Giulietti, A.M.; Melhem, T.S.; Bittrich, V. \& Kameyama, C. (eds.). Flora Fanerogâmica do estado de São Paulo. Instituto de Botânica, São Paulo. Vol. 2, pp. 229-259.

Marques, M.C.M. \& Peixoto, A.L. 2007. Estudo taxonômico de Polygala subgênero Ligustrina (Chodat) Paiva (Polygalaceae). Rodriguésia 58: 95-146.

Martinelli, G.; Santos-Filho, L.A.F.; Penedo, T.S.A. \& Valente, A.S.M. 2013. Polygalaceae. In: Martinelli, G. \& Moraes, M.A. (eds.). Livro vermelho da flora do Brasil. Andrea Jakobsson Estúdio, Rio de Janeiro. Pp. 887-888.

Melo, A.; Alves-Araújo, A. \& Alves, M. 2010. Burmanniaceae e Gentianaceae da Usina São José, Igarassu, Pernambuco. Rodriguésia 61: 431-440.

Mori, S.A.; Mattos-Silva, L.A.; Lisboa, G. \& Coradin, L. 1985. Manual de manejo do herbário fanerogâmico. Centro de Pesquisas do Cacau, Ilhéus. 97p.

Nogueira, F.L.P.; Fernandes, S.B.O.; Reis, G.M.; Matheus, M.E.; Fernandes, P.D.; Lage, C.L.S. \& Menezes, F.S. 2005. Atividade analgésica e antiedematogênica de Polygala paniculata L. (Polygalaceae) selvagem e obtida por micropropagação. Revista Brasileira de Farmacognosia 15: 310-315. 
Lüdtke, R.; Souza-Chies, T.T. \& Miotto, S.T.S. 2013. Polygala na Região Sul do Brasil. Hoehnea 40: 1-50.

Paiva, J.A.R. 1998. Polygalarum Africanarum et Madagascariensium prodomus atque gerontogaei generis Heterosamara Kuntze, a genere Polygala segregati et a nobis denuo recepti, synopsis monographica. Fontqueria 50: 1-346.

Pastore, J.F.B. \& Cavalcanti, T.B. 2006. Polygalaceae. In: Cavalcanti, B.T. (org.). Flora do Distrito Federal, Brasil. Vol. 5. Embrapa, Recursos Genéticos e Biotecnologia, Brasília. Pp. 109-179.

Pastore, J.F.B. 2010. Bredemeyera hebeclada, a New Combination in Polygalaceae. Novon 20: 314-316.

Pastore, J.F.B.; Cardoso, D.B.O.S. \& Aymard, C.G.A. 2010. A synopsis, new combinations, and synonyms in Acanthocladus (Polygalaceae). Novon 20: $317-$ 324.

Pastore, J.F.B. \& Abbott, J.R. 2012. Taxonomic notes and new combinations for Asemeia (Polygalaceae). Kew Bulletin 67: 801-813.

Pastore, J.F.B. 2012. Caamembeca: generic status and new names for Polygala subgenus Ligustrina (Polygalaceae). Kew Bulletin 67: 1-8.

Pastore, J.F.B. \& Moraes, P.L.R. 2013. Generic status and lectotypifications for Gymnospora (Polygalaceae). Novon 22: 304-306.

Pessoa, E. \& Alves, M. 2012. Flora da Usina São José, Igarassu, Pernambuco: Orchidaceae. Rodriguésia 62: 341-356.

Pizzollatti, M.G.; Cristiano, R.; Monache, F.D. \& Branco, A. 2002. Artefatos cumarínicos isolados de Polygala paniculata L. (Polygalaceae). Revista Brasileira de Farmacognosia 12: 21-26.
Pontes, T.A.; Andrade, I.M. \& Alves, M. 2010. Flora da Usina São José, Igarassu, Pernambuco: Araceae. Rodriguésia 61: 689-704.

Ribas, C.M; Meotti, F.C.; Nascimento, F.P.; Jacques, A.V.; Dafre, A.L.; Rodrigues, A.L.S.; Farina, M.; Soldi, C.; Mendes, B.G.; Pizzolatti, M.G. \& Santos, A.R.S. 2008. Antinociceptive Effect of the Polygala sabulosa Hydroalcoholic Extractin Mice: Evidence for the Involvement of Glutamatergic Receptors and Cytokine Pathways. Basic \& Clinical Pharmacology \& Toxicology 103: 43-47.

Santos, S.O. \& Alves, M. 2012. Flora da Usina São José, Igarassu, Pernambuco: Lauraceae. Rodriguésia 63: 689-703.

Souza, V.C. \& Lorenzi, H. 2008. Botânica sistemática: guia ilustrado para identificação das famílias de Fanerógamas nativas e exóticas no Brasil, baseado no APG II. $2^{\text {a }}$ ed. Instituto Plantarum, Nova Odessa. $704 \mathrm{p}$.

Thiers, B. [continuamente atualizado]. Index Herbariorum: a global directory of public herbaria and associated staff. New York Botanical Garden's Virtual Herbarium. Disponível em <http:// sweetgum.nybg.org/ih>. Acesso em 15 abril 2014.

Veloso, H.P.; Rangel-Filho, A.L. \& Lima, J.C.A. 1991. Classificação da vegetação brasileira, adaptada a um sistema universal. Fundação Instituto Brasileiro de Geografia e Estatística - IBGE, Rio de Janeiro. $124 \mathrm{p}$.

Wurdack, J.J. \& Smith, L.B. 1971. Poligaláceas. In: Reitz, P.R. (ed.). Flora Ilustrada Catarinense. Vol. 1. Conselho Nacional de Pesquisas, IBDF. Herbário Barbosa Rodrigues, Itajaí. Pp. 3-70.

\section{Lista de exsicatas}

Albuquerque, N.A. 586 (9). Alves-Araújo, A. 144 (5), 624 (2), 728 (9), 1066 (5). BHRG 476 (8). Cavalcanti, D. 39 (3), 214 (5), 215 (1), 216 (7), 365 (2), 626 (9). Farney, C. 4138 (4). García, J.D. 1405 (4). Lombardi, J.A. 6995 (4). Maciel, J.R. 325 (6). Melo, A. 35 (3), 98 (6), 118 (8), 350 (3). Ojima, P.Y. 63 (1), 67 (7). Pessoa, E. 91 (1). 